\title{
Separation and Quantification of Attached Mortar in Recycled Concrete Aggregates
}

\section{S. Braymand, S. Roux, H. Fares, K. Déodonne \& F. Feugeas}

\section{Waste and Biomass Valorization}

ISSN 1877-2641

Waste Biomass Valor

DOI 10.1007/s12649-016-9771-2

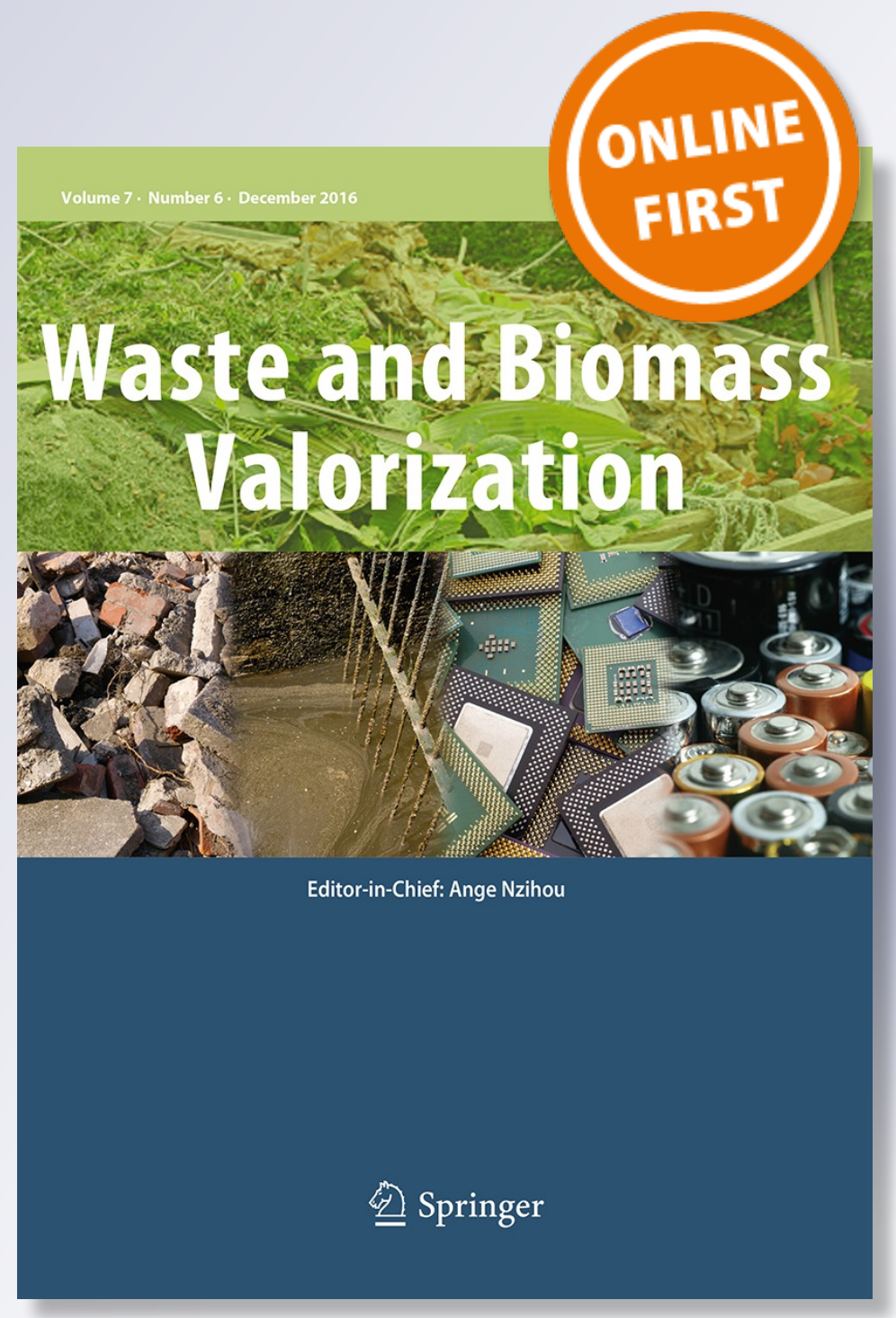

照 Springer 
Your article is protected by copyright and all rights are held exclusively by Springer Science +Business Media Dordrecht. This e-offprint is for personal use only and shall not be selfarchived in electronic repositories. If you wish to self-archive your article, please use the accepted manuscript version for posting on your own website. You may further deposit the accepted manuscript version in any repository, provided it is only made publicly available 12 months after official publication or later and provided acknowledgement is given to the original source of publication and a link is inserted to the published article on Springer's website. The link must be accompanied by the following text: "The final publication is available at link.springer.com". 


\title{
Separation and Quantification of Attached Mortar in Recycled Concrete Aggregates
}

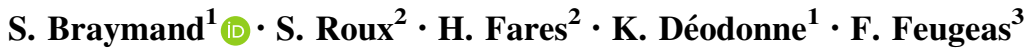

Received: 4 April 2016/Accepted: 10 November 2016

(C) Springer Science+Business Media Dordrecht 2016

\begin{abstract}
Construction and demolition waste stream has generated news materials that may be re-introduced into new concrete, e.g. as recycled aggregates. The specific feature of recycled concrete aggregates is the presence of hardened mortars influencing their behaviour. This study aims to distinguish processes that allow the complete separation and quantification of attached mortar. An important point is that the laboratory developed method has to be transferable on a wider scale to be exploited on a real recycling platform. This study is linked to the recybeton national research project involving public research laboratories, institutes and private companies. After a short literature review, pointing out the relevant processes, several methods are tested in laboratory conditions to determine their efficiency. They are based on mechanical, chemical and physical principles. Efficiencies are evaluated by measuring mass losses, density variations and by carrying out visual comparisons. It appears that not any one method is $100 \%$ satisfactory as aggregates are never completely cleaned and/or are damaged. Furthermore, the global efficiency of the process is difficult to determine because of the lack of knowledge of primary aggregate properties or because of property changes during treatment. The most promising methods, of those investigated in this study, seem to be combined thermal-mechanical processes.
\end{abstract}

S. Braymand

s.braymand@unistra.fr

1 ICube UMR 7357, Strasbourg University, 2 rue Boussingault, 67000 Strasbourg, France

2 IJL UMR 7198, Rue du Doyen Urion, Le Montet, CS 90137, 54601 Villers les Nancy, France

3 ICube UMR 7357, INSA Strasbourg, 24 Boulevard de la Victoire, 67084 Strasbourg, France
Keywords Recycled concrete aggregates · Attached mortar $\cdot$ Separation $\cdot$ Experimental process
Abbreviations
RCA Recycled concrete aggregate
RAC Recycled aggregate concrete
MDE Micro deval test
LA Los angeles test
HSC Hydrated silicate calcium
Symbols
Temp Temperature
Sat Saturation
$\rho\left(\mathrm{g} / \mathrm{cm}^{3}\right)$ Density
$\Delta \mathrm{m} \quad$ Mass loss
W (\%) Absorption coefficient

\section{Introduction}

In order to decrease resource consumption and demolition waste generation, materials from building deconstruction are now studied with the aim of re-introducing them into new concrete, e.g. as recycled aggregates [1,2]. The study, presented here, deals with the prospect of a lack of natural aggregates requiring the use of aggregates from recycling [3]. The physic-chemistry of recycled concrete aggregates, like their high absorption, low strength, or specific morphology, limits their direct use as aggregates and requires pretreatment if $100 \%$ re-use is expected. This operation aims at separating primary aggregates and mortar for re-use as aggregates for concrete. Then, the residual mortar obtained could be reintroduced into cement production plants. Recycled aggregates may comprise of various sized particles [4-6]: 
- Fine elements $(0-500 \mu \mathrm{m})$, mainly composed of hardened cement paste, primary crushed aggregates and anhydrous cement;

- Sands, fine aggregates including the fine elements (0-4 mm), mainly composed of primary aggregates and mortar (primary sand, dry and hydrated cement);

- Gravel, coarse aggregates ( $>4 \mathrm{~mm}$ ), have a constitution close to recycled sand with lower residual mortar content.

Thus, the recycled aggregates consist of aggregates coated with primary mortar: separated or attached (Fig. 1; [2]). The presence of this primary mortar is responsible for the different behavior of recycled concrete aggregates and natural aggregates [7-9]. The range of these alterations is dependent on the amount of primary mortar included in the recycled elements [6].

Different processes used to separate primary aggregate and mortars are discussed in the literature (Table 1; [10]). These methods, based on mechanical (wear, fragmentation, etc.), chemical (acid attack) or physical (heat treatment) principles, use differences of properties between the aggregates and the cement paste [10]. Few studies offer a multi-criteria comparative analysis of these methods [10], and efficiency is rarely discussed, this paper provides this critical analysis.

For this purpose, a short literature review is proposed in order to collect processes which have been experimentally tested in our laboratory. Thus, several methods or combinations of methods are tested in the laboratory to determine their efficiency: mechanical wear test, sandblasting, chemical attack by hydrochloric acid, hot and cold thermal cycle and microwave (see Table 1). Concerning the hot or cold thermal processes combined with a mechanical treatment, a 12 phase experiment allows for a thorough knowledge of treatment efficiency. The efficiency, defined

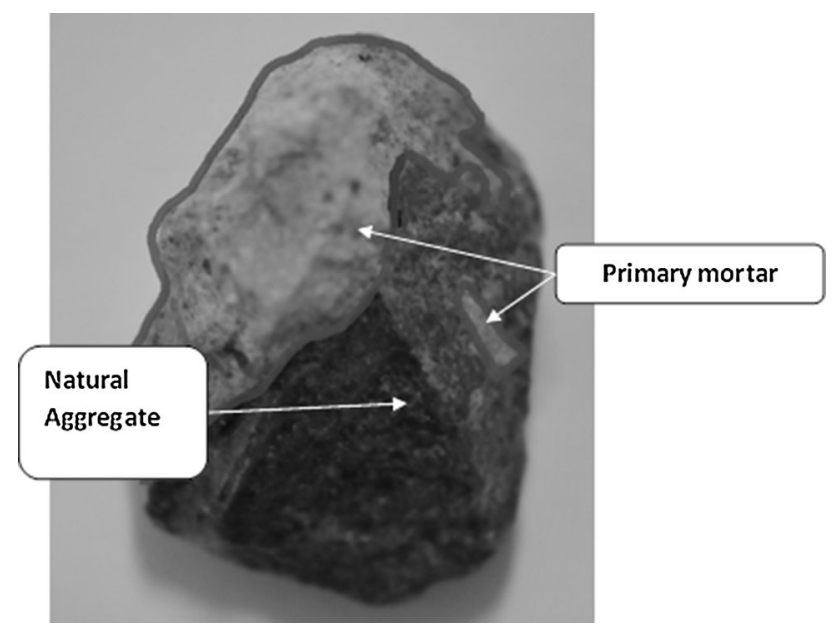

Fig. 1 Recycled concrete aggregate constitution [5]

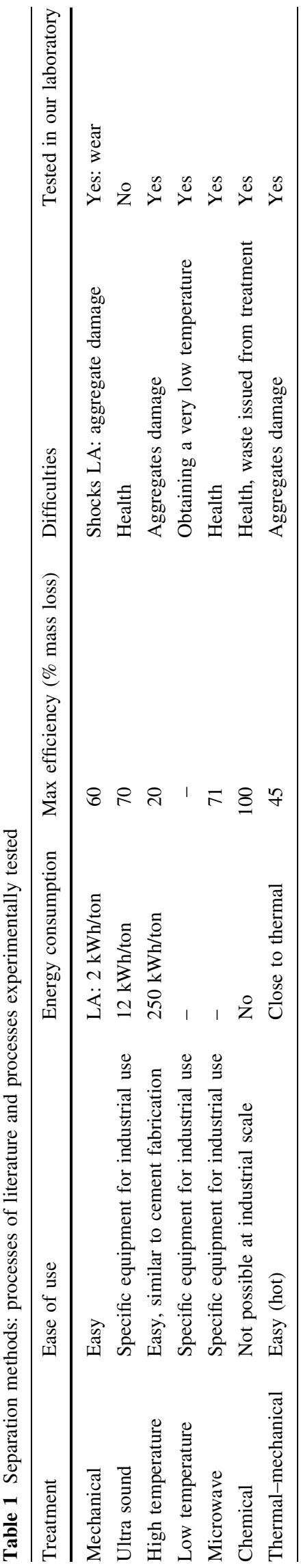


by the separation ratio or the quantity of attached mortar, is analyzed using mass loss, density variation measurements and visual comparisons. The definition of this efficiency concept and the mortar content denomination are also discussed.

This study is linked to the national research project [12] (complete recycling of concrete) involving public research laboratories, institutes and private companies. An important aspect of this work is to ensure that developed methods in the laboratory have to be transferable on a wider scale to be exploited on a real recycling platform. The final recybeton aim is to edit recommendations promoting the complete recycling of concrete.

\section{Short Review of Processes}

\section{Mechanical Treatments}

The mechanical treatments of aggregates allow mortaraggregate separation by shocks (based on Los Angeles standard test [13]: LA) or abrasion (based on micro-deval standard test [14]: MDE). The efficiency of the LA method, up to $60 \%$ mass loss after sieving, depends on the number of balls used, the amount of processed materials, the rotation rate and the treatment length [15]. However, efficiency may be called into question when considering the amount of natural aggregates to be crushed. Moreover, one limitation of this method is its energy consumption to obtain such a mass loss (min 300 revolutions). It requires a compromise between efficiency, treatment duration, noise and energy consumption [10]. Although, authors don't indicate an estimation of energy consumption, this consumption can be estimated around $2 \mathrm{kWh} /$ ton of recycled aggregates concerning the only shock phase (without sieving).The efficiency of the MDE method is lower than when using separation by shocks, depending on its duration. However, it avoids high fragmentation of primary aggregates and, therefore, decreases damage of their morphological integrity, especially that of rolled aggregates.

Another method called "smart crusher", based on the optimization of the crushing method of recycled concrete, was found to produce much more recycled concrete fine elements and cleaner aggregate than a conventional crushing method. It is based on a smart combination of pressure and abrasion [16, 17]. According to the authors, no supplementary cleaning treatment is needed after crushing and material from crushing could be re-used as sand or fine addition in concrete. The process efficiency is evaluated by the particle size distribution comparison between aggregates issued from two crushing methods. Authors indicate that the use of the smart crusher leads to obtain an aggregate easily recyclable in concrete. However, this analyze is only performed with fine aggregate $(<2 \mathrm{~mm})$ and the properties of the treated aggregate are not evaluated (density, water absorption, visual aspect...).

\section{Ultra-Sound Treatments}

This method is based on the stresses generated by high frequency sound waves which damage the bonding between aggregates and cement paste. The supply of energy over the entire surface increases the separation efficiency whilst reducing the degradation of initial aggregates. Many factors influence the efficiency of this method [18]: aggregate size, applied voltage, capacitor capacitance, electrode spacing and number of pulses. For the verification of the crushing and separation effect, different characteristic values were determined (particle size distribution, amount of attached cement stone, content of cement paste).

The efficiency of this method can reach a higher level than conventional mechanical treatments by crushing (jaw crusher, hammer) but it depends on the aggregate size: the detachment rate is about $40 \%$ for a fine aggregate $(<4 \mathrm{~mm})$ and $70 \%$ for a coarse aggregate $(<24 \mathrm{~mm})$. The efficiency of this method has to be considered regarding its high energy consumption. The estimation of consumed energy is about $12 \mathrm{kWh} /$ ton of recycled aggregates [18].

\section{Thermal Treatments}

\section{High Temperature Treatment}

High temperature thermal methods are based on the influence of the temperature increase on the cement matrix and on the aggregates: damage of cement hydrates, differential strains of hardened concrete constituents and lower strength of the mortar (thermal stresses). The recycled aggregate concrete is heated for several hours between 300 and $600{ }^{\circ} \mathrm{C}$ (depending on the strength of the mortar and the types of natural aggregates [19]) and then sieved to separate mortar and natural aggregates. Water immersion of RCA (saturation of the mortar), prior to heat treatment, improves the efficiency of the separation processes. Indeed, the transformation of water into steam generates an increase in the internal pressure favorable to mortar cracking. The maximum separated mortar proportion can reach $20 \%$ [20]. Rapid cooling of RCA, after the heating cycles, produces further thermal shocks, thereby, improving process efficiency, which is probably due to "prevented thermal expansion" [21]. Thermal separation by heating is easy to implement but the actual energy consumed is very high, it can be estimated at $250 \mathrm{kWh} /$ ton for $1 \mathrm{~h}$ at $600{ }^{\circ} \mathrm{C}$. Moreover, high temperatures can create high internal stresses in natural aggregates. After $600{ }^{\circ} \mathrm{C}$ heat treatment, 
the tensile strengths of natural aggregates are reduced by $60 \%$ [20]. This reduction rate significantly depends on the origins of the primary natural aggregates and their mechanical properties.

\section{Low Temperature Treatment}

These methods are based on freeze-thaw cycle effects applied on saturated RCA, which generate damage caused by internal pressures (transformation of water in the pores into ice leads).

The saturation state (dry, saturated, saturated-immersed) conditions the aggregate's resistance to freezing and thawing $[22,23]$. This method can produce a large amount of cleaned natural aggregates but requires a high number of freeze-thaw cycles over a period of several weeks.

\section{Microwave Treatment}

Microwave treatment is based on electromagnetic properties of recycled concrete and its influences on the increasing local temperature. Due to the different sensitivity to waves between the mortar and the natural aggregates, thermal stresses are mainly generated in the interface mortars-aggregate. This treatment reduces the risk of degradation of natural aggregates because of its lower temperatures and duration compared to conventional heating treatments. Parameters such as the duration of treatment or generator power can be adjusted.

The efficiency of microwaves depends on the size and type of recycled aggregates [11,24]. The treatment is more efficient for coarse aggregates than for fine aggregates, about 71 and 19\% release, respectively [26]. Treatment by microwaves is less efficient on calcium silicate aggregates: specific chemical reactions between aggregate and cement paste in the interfacial transition zone affect the reactivity of recycled aggregates subjected to microwaves [25].

The pre-saturation of RCA can improve this process's efficiency (mortar content decreased from 47 to 24\%). The effectiveness of treatment can also be increased by successive applications of the process [26].

\section{Chemical Treatment}

RCA is composed of two different mineral materials, natural aggregates and alkaline cement paste, which offer different sensitivities to acido-basic reactions [27]. The efficiency of acid treatment added to a water rinse depends on mortar porosity, the nature of aggregates, the acid solution choice and the treatment conditions (volume of material to be processed, temperature, treatment duration, static and dynamic processing) [28]. The most effective acids with silica or granitic aggregates are sulfuric and hydrochloric acids $\left(\mathrm{H}_{2} \mathrm{SO}_{4}\right.$ and $\left.\mathrm{HCl}\right)$. However, these aggregates cannot be treated using hydrofluoric acid (HF) which generate the dissolution of their main components (Quartz, Feldspar, and Mica) [29]. Limestone aggregates are insoluble in salicylic acid while some components of the cement matrix are soluble $\left(\mathrm{C}_{2} \mathrm{~S}\right.$, $\mathrm{C}_{3} \mathrm{~S}, \mathrm{Ca}(\mathrm{OH})_{2}, \mathrm{CSH}$, ettringite). If optimum conditions are implemented, the efficiency of this heat treatment can reach a rate of $100 \%$.

\section{Thermal-Mechanical Treatments}

These methods aim to combine the effects of heat treatment, hot or cold, and a mechanical post-treatment. Thermal-mechanical treatment, such as the hot-MDE proposed by Shima et al. [19], is of sufficient efficiency: $35-45 \%$ of clean gravels, $30-35 \%$ of clean sand and $18-35 \%$ of fine elements after treatment. Many parameters influence these results: temperature, primary concrete properties, grinding intensity et cetera. Cold thermalmechanical treatments combine the exposing of the damaged cement matrix to freeze-thaw cycles and mechanical separation of the mortar. Due to the potentially high duration of this process, no specific study has this as its principle focus.

\section{Other Treatments}

Other methods are mentioned in the literature but they have not been the main objective of extensive studies concerning the problem of paste-aggregate separation.

\section{Hydraulic Jet}

The high pressure water jet method is used for cutting different materials and should be adapted to the separation of mortar and aggregate [30]. During the treatment of a porous material, such as concrete, the water jet leads to the dispersion of a significant amount of energy in a small area creating a phenomenon of erosion and a wearing of the material. The method efficiency depends on the energy created by the jet of water in contact with the material and on the distance between the jet nozzle and the material.

\section{Thermal-Chemical Treatment}

The thermal-chemical treatment combines two effects: the chemical degradation of recycled concrete aggregate by exposure to sodium sulfate solution $\left(\mathrm{Na}_{2} \mathrm{SO}_{4}\right)$ and mechanical separation of the mortar by freeze-thaw cycles. Treatment efficiency depends on a duration of more than 7 days, thus, limiting its industrial development [19, 31]. 
Table 2 Properties of RAC and primary component

\begin{tabular}{llll}
\hline Aggregate origin & & & \\
\hline Designation & Origin & Place & Aggregate \\
\hline GR2 & Industrial & Strasbourg, France & $0-20 \mathrm{~mm}$ \\
GR4 & Industrial recybeton & Gonnesse, France & $4-10$ and 10-20 mm \\
GR6 & Homemade & Strasbourg, France & $0-20 \mathrm{~mm}$ \\
GR8 & Homemade & Nancy, France & $0-80 \mathrm{~mm}$ \\
\hline
\end{tabular}

Composition of primary concrete (GR6 and GR8)

\begin{tabular}{llllll}
\hline$\left(\mathrm{kg} / \mathrm{m}^{3}\right)$ & Rolled $0 / 4 \mathrm{~mm}$ & Rolled $4 / 8 \mathrm{~mm}$ & Rolled $8 / 16 \mathrm{~mm}$ & Total water & Cement type and content [33] \\
\hline GR6 & 700 & 100 & 1000 & 200 & CEM I-52.5-350 \\
GR8 & 790 & 1024 & & 200 & CEM IIB-32.5R-340 \\
\hline
\end{tabular}

Properties of aggregates used for primary concrete (GR6 and GR8)

\begin{tabular}{lllll}
\hline & & Fine & Medium & Coarse \\
\hline GR6 & Water absorption $(\%)$ & $1.06 \pm 0.28$ & $2.03 \pm 0.02$ & $1.43 \pm 0.06$ \\
GR6 & Effective density ( $\rho$ rd) & $2.86 \pm 0.21$ & $2.57 \pm 0.08$ & $2.58 \pm 0.02$ \\
GR8 & & 2.56 & 2.55 & \\
GR6 & Bulk ssd density ( $\rho$ ssd) & $2.89 \pm 0.2$ & $2.62 \pm 0.08$ & $2.62 \pm 0.01$ \\
GR6 & Bulk density ( $\rho$ a) & $2.95 \pm 0.2$ & $2.71 \pm 0.09$ & $2.68 \pm 0.01$ \\
\hline
\end{tabular}

\section{Chemical-Mechanical Treatment}

RCA can be treated by combining the effects of acid attack and mechanical treatment. This process consists in immersing the crushed concrete in an acid solution before submitting it to mechanical treatment like Los Angeles. This type of short-duration treatment could be used as a pre-treatment to remove the coarser particles [32].

\section{Synthesis and Balance Sheet}

A result of the literature review is synthesized Table 1 concerning the main treatments. Processes experimentally tested in the continuation of the study are also listed in Table 1.

\section{Materials and Methods}

In the following part, some of the previously described methods are tested in the laboratory with the aim of determining their efficiency. Their efficiency is analyzed using mass loss, density variation measurements and visual comparisons.

\section{Recycled Concrete Aggregate}

Four recycled aggregates are studied: Two recycled aggregates from industrial platforms and two homemade recycled aggregates whose compositions and properties of primary concrete are known (Table 2).

\section{Methods}

\section{Treatments and measurements}

Simple processes are described on Fig. 2: mechanical wear, sandblasting, chemical attack, microwave, and hot or cold treatment. At the end of the treatments, samples are sieved or sorted to separate the removed mortar from the cleaned aggregate. Next, mass loss, density, water absorption coefficient measurements, or visual checks are carried out at various stages of the treatments. These measurements are used to assess the efficiency of the treatments. When the properties of the primary aggregates are known (GR6, GR8), efficiency is evaluated by a comparison of values. Although the aim of this study is not to evaluate the quantity of primary mortar contained in the recycled aggregate, sometimes, such an estimation will be used as the efficiency criteria.

Combined thermal-mechanical treatments are described in Figs. 3, 4. The phases of the thermal and thermal-mechanical processes are detailed hereafter.

\section{Hot Thermal Cycle}

Several combinations of heating/post-treatment cycles are made. The three first experiments are carried out to identify 


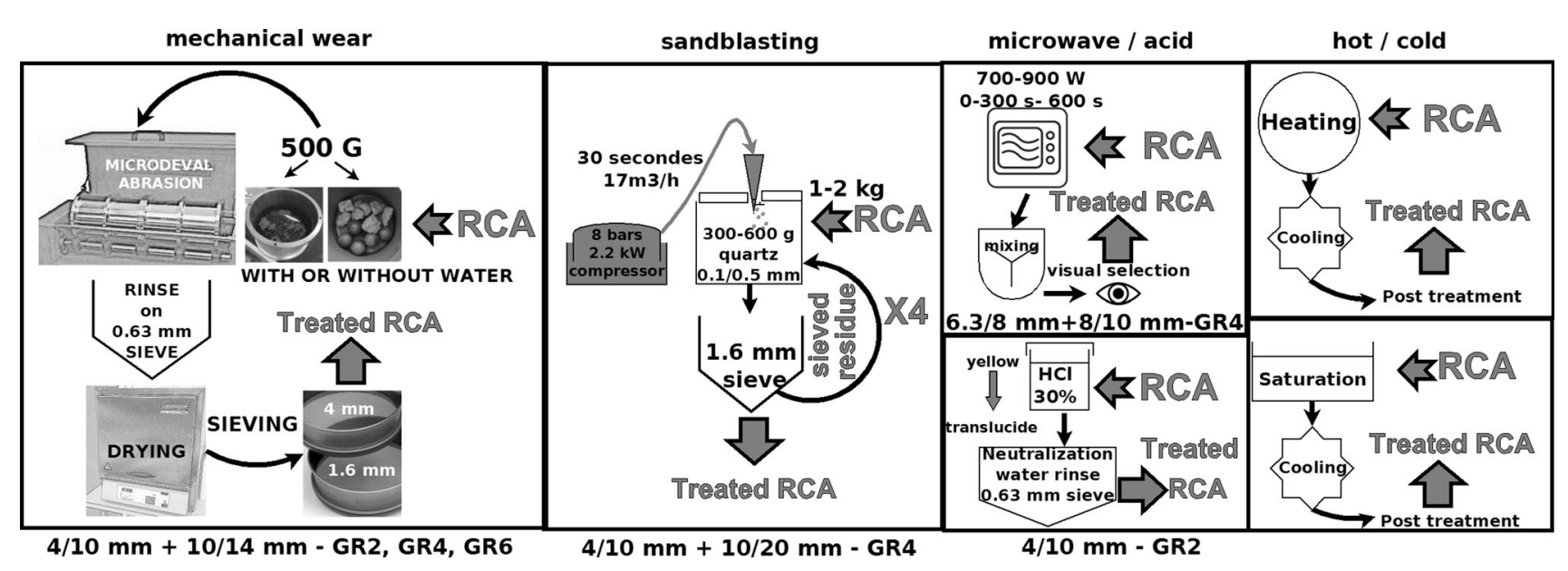

Fig. 2 Simple processes

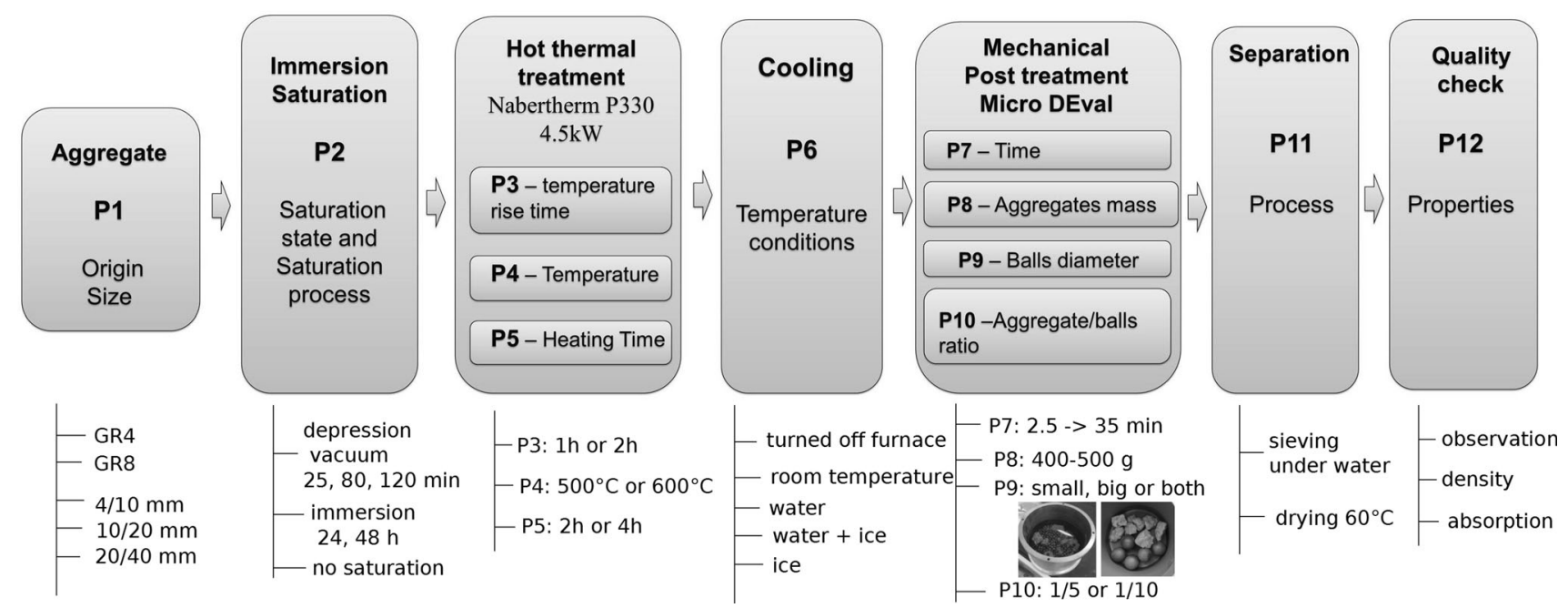

Fig. 3 Hot thermal-mechanical experimental design

influential parameters. These experimentations are summarized in Table 3.

An optimized combined process is performed. It consists of a complete thermal-mechanical treatment. The experimental design is available with 12 parameters. Sequencing the method (Fig. 3) allows variations of the parameters. Tests are performed with the parameters detailed in Table 4.

\section{Cold Thermal Cycle}

The principle of the cold thermal method is to saturate aggregates with water, then, to submit them at a low temperature. On applying light (e.g. mixer) mechanical treatment the mortar can be separated from the parent aggregate. Several thermal cycles and aggregate saturation conditions are tested. The two first experiments are summarized in Table 5.

After which, the optimized process is performed. It consists of thermal-mechanical treatment. Thermal phase consist of freeze-thaw cycles. Similar to hot thermal- mechanical treatment, the experimental design is sequenced of 12 steps (Fig. 4). Tests are performed with the parameters detailed in Table 6.

\section{Experimental Results}

\section{Wear Mechanical Test (Micro Deval)}

In a first approach, the efficiency of the process is checked using mass loss. It's considered that mass loss is composed of primary mortar (Fig. 5).

At first sight, the process seems efficient because mass loss is important, mainly for the smaller aggregates (4/ $10 \mathrm{~mm}$ ) and with an application time greater than $30 \mathrm{~min}$ ( $>10 \%$ on a $1.6 \mathrm{~mm}$ sieve). The results confirm that the smaller the aggregate size, the higher the mortar content found. As expected, an increase of application time increases mass loss. 


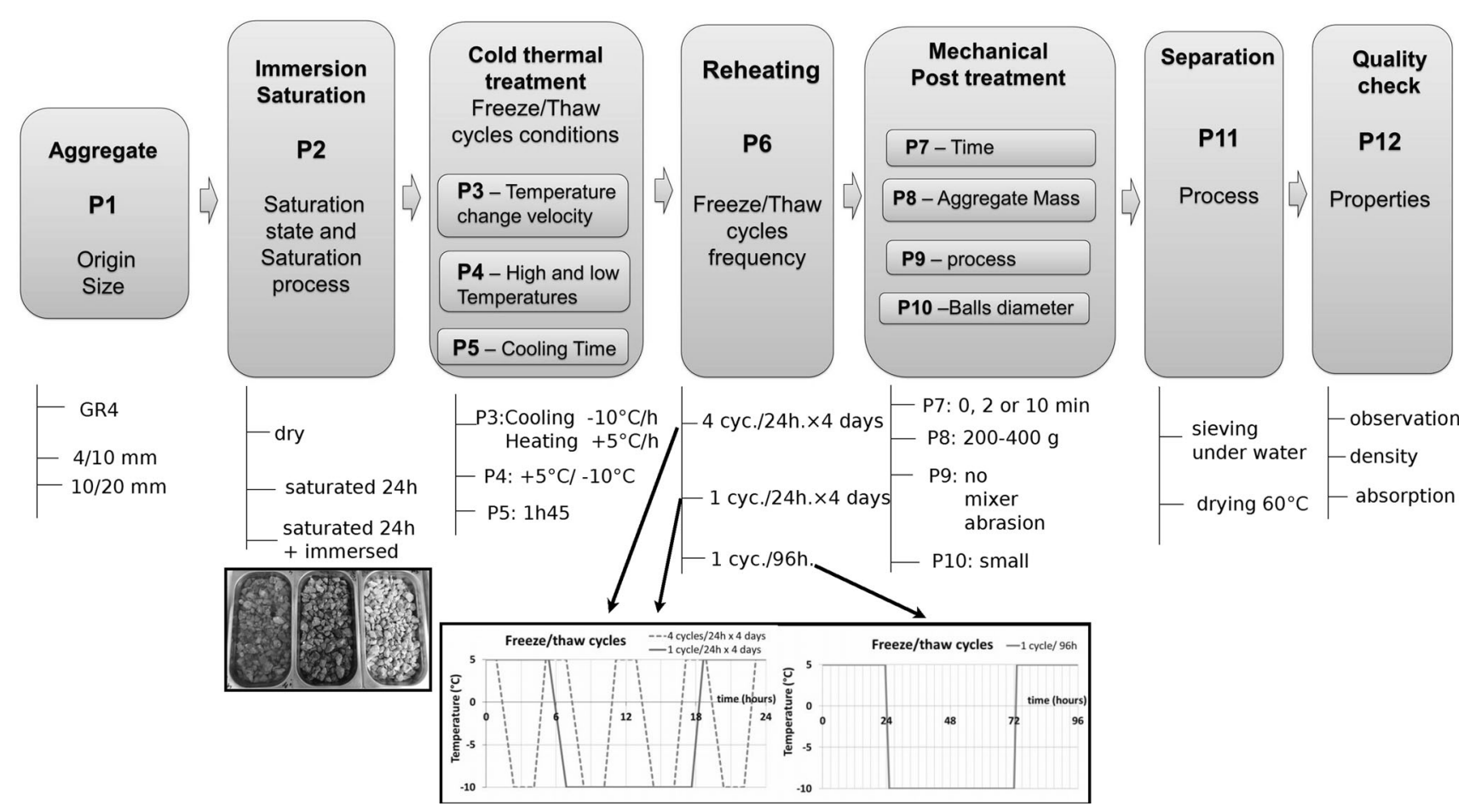

Fig. 4 Cold thermal-mechanical process experimental design

Table 3 Hot thermal cycle-firsts experimentations

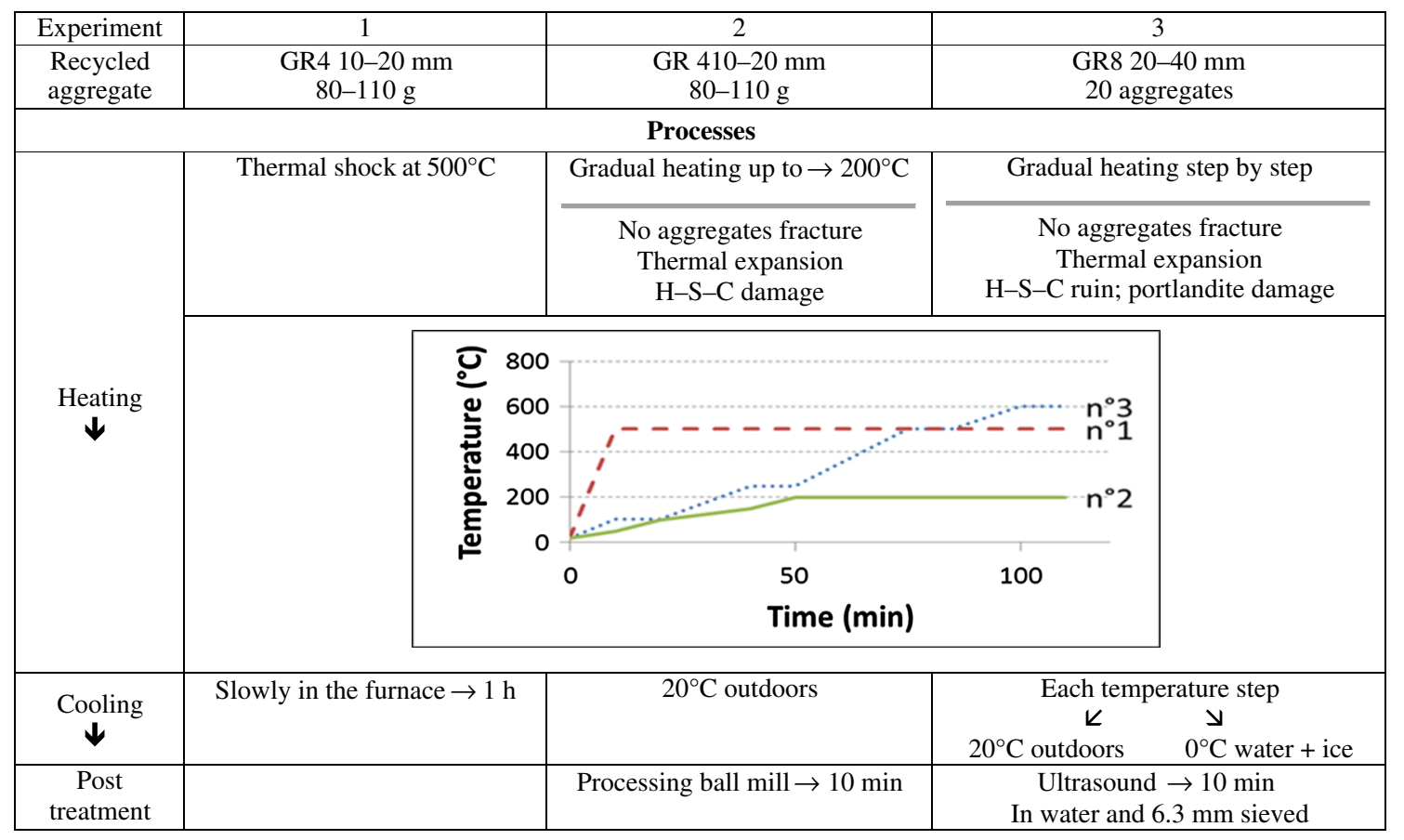

However, in addition to incorporating a part of the primary aggregate worn by the test in the estimating amount of primary mortar, there is no guarantee that the treatment removes all the mortar. Moreover, it's not easy to choose a relevant sieve size to qualify the primary mortar or cement paste. Thus, when the composition of the primary concrete is unknown, an estimation of the mortar content can't be done and compared to mass loss. And, even if the 
Table 4 Parameters-hot thermal mechanical process

\begin{tabular}{llllllllllll}
\hline No. & P1 & P2 & P3 $(\mathrm{h})$ & P4 $\left({ }^{\circ} \mathrm{C}\right)$ & P5 $(\mathrm{h})$ & P6 & P7 (min) & P8 & P9 & P10 & P11 \\
\hline 16 & GR4 10/20 & No sat. & 1 & 600 & 2 & Room temp. & 10 & 421 & No & $\sim 1 / 5$ & Sieving \\
19.1 & GR4 10/20 & No sat. & 1 & 600 & 2 & Room temp. & 10 & 501 & Small & $\sim 1 / 5$ \\
19.2 & GR4 10/20 & No sat. & 1 & 600 & 2 & Room temp. & 10 & 502 & Big & $\sim 1 / 5$ \\
27.4 & GR8 32/64 & Pre sat 48 h & 1 & 600 & 4 & Ice & $5+25$ & 502 & Big + small & $\sim 1 / 5$ \\
\hline
\end{tabular}

Parameters' signification (P1-P11) are described on Fig. 3

Table 5 Cold thermal cycle-firsts experimentations

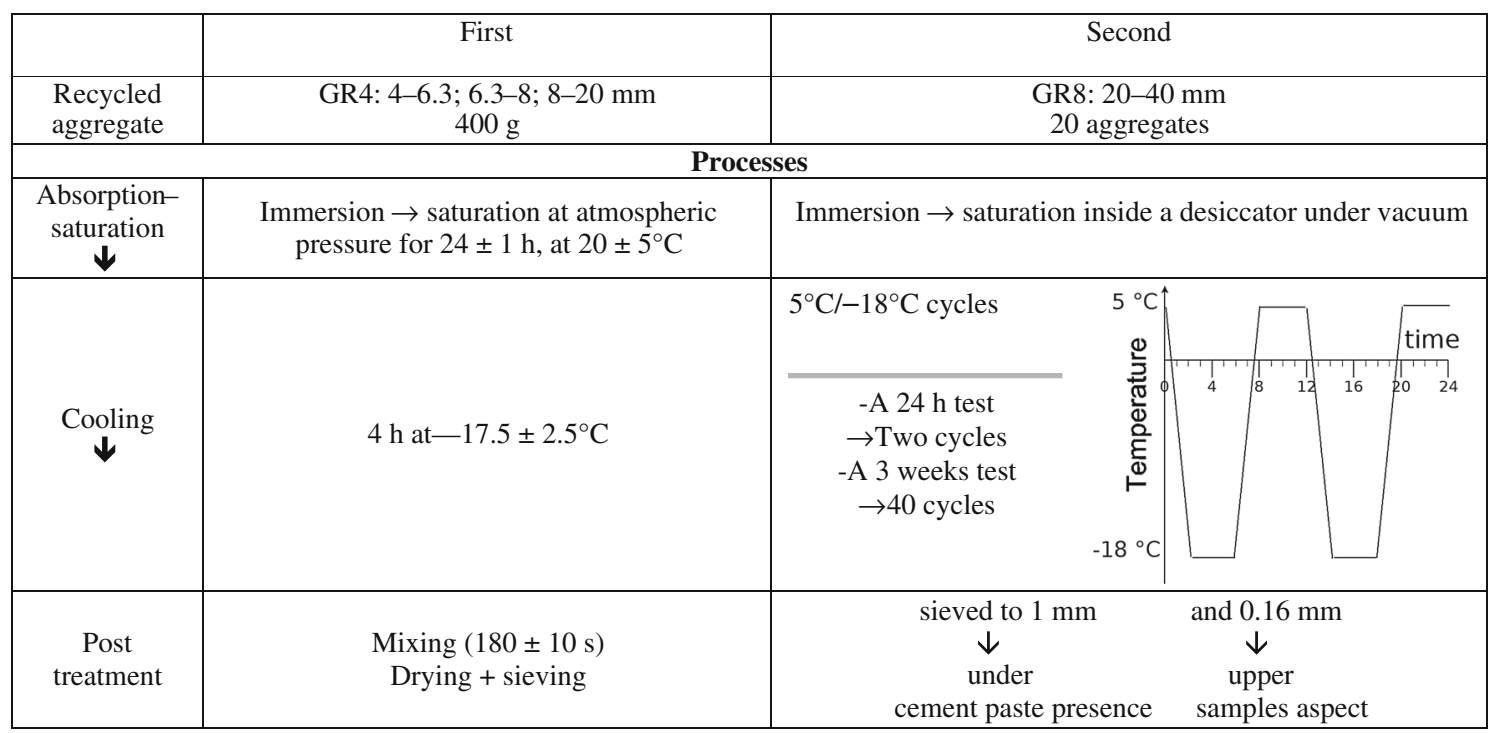

composition is known, the composition of the mortar collected post treatment is unknown (sand proportion). So, a study based on mass loss determination is insufficient.

Without knowledge of the primary aggregate densities efficiency can't be totally validated. However, the visual check indicates that an application time of $120 \mathrm{~min}$ is needed. Unfortunately, it leads to the damaging of the primary aggregate (visual check), which could lead to loss of properties, for example the decrease of density observed for GR2 and GR6 (Fig. 6). Furthermore, mortar can be unstuck but not removed, thus, voids are created between the mortar and primary aggregate. Moreover, standard deviation of effective density measurement is near to $0.07 \mathrm{~g} / \mathrm{cm}^{3}$ for coarse recycled concrete aggregate $(4-14 \mathrm{~mm})$. This involves being cautious regarding result interpretation.

The measurements of absorption coefficients confirm that the treatment is not complete since the values obtained are higher than those usually found for natural aggregate (Fig. 7).

The detailed results on GR6 (Table 7) don't emphasize the relevant sieve to distinguish mortar from aggregate because the difference between 1.6 and $4 \mathrm{~mm}$ is not significant and, by comparing primary aggregate properties, they confirm that the separation is not complete.

To obtain a clean aggregate it is necessary to apply wear over a long period. However, the removed material is not only composed of primary mortar. So a high value of mass loss does not ensure effective cleaning.

\section{Sandblasting}

This process is not of interest because of its high consumption of sand versus its low efficiency (Table 8). However, this method could be used in post processing to separate mortar removed by another previous treatment (e.g. thermal).

\section{Chemical Attack by Hydrochloric Acid}

These results and visual checks show that this method allows the dissolution of the cement matrix. The mass loss proportion is high: $26 \%$ on the $4 \mathrm{~mm}$ sieve and $38 \%$ on the $5 \mathrm{~mm}$ sieve. However, such tests cannot be applied to industrial use for two reasons. Firstly, the post treatment 
Table 6 Parameters-cold thermal mechanical process

\begin{tabular}{|c|c|c|c|c|c|c|c|c|c|c|c|}
\hline No. & $\mathrm{P} 1$ & $\mathrm{P} 2$ & P3 & $\mathrm{P} 4$ & P5 & P6 & $\mathrm{P} 7$ & P8 & P9 & P10 & $\mathrm{P} 11$ \\
\hline 1 & \multirow[t]{9}{*}{ GR $4 / 10 \mathrm{~mm}$} & Dry & \multirow{9}{*}{$\begin{array}{r}\text { Cooling }-10^{\circ} \mathrm{C} / \mathrm{h} \\
\text { heating }+5^{\circ} \mathrm{C} / \mathrm{h}\end{array}$} & \multirow[t]{9}{*}{$+5^{\circ} \mathrm{C} /-10^{\circ} \mathrm{C}$} & \multirow[t]{9}{*}{ 1h 45} & \multirow{9}{*}{$\begin{array}{l}4 \text { Cycles/ } \\
24 \mathrm{~h} \times 4 \text { days }\end{array}$} & 0 & 200 & No & - & \multirow[t]{9}{*}{ Sieving } \\
\hline 2 & & Dry & & & & & 2 & 400 & Mixer & - & \\
\hline 3 & & Dry & & & & & 10 & 400 & Abrasion & Small & \\
\hline 4 & & Saturated & & & & & 0 & 200 & No & - & \\
\hline 5 & & Saturated & & & & & 2 & 400 & Mixer & - & \\
\hline 6 & & Saturated & & & & & 10 & 400 & Abrasion & Small & \\
\hline 7 & & Immersed & & & & & 0 & 200 & No & - & \\
\hline 8 & & Immersed & & & & & 2 & 400 & Mixer & - & \\
\hline 9 & & Immersed & & & & & 10 & 400 & Abrasion & Small & \\
\hline
\end{tabular}

Parameters' signification (P1-P11) are described on Fig. 4

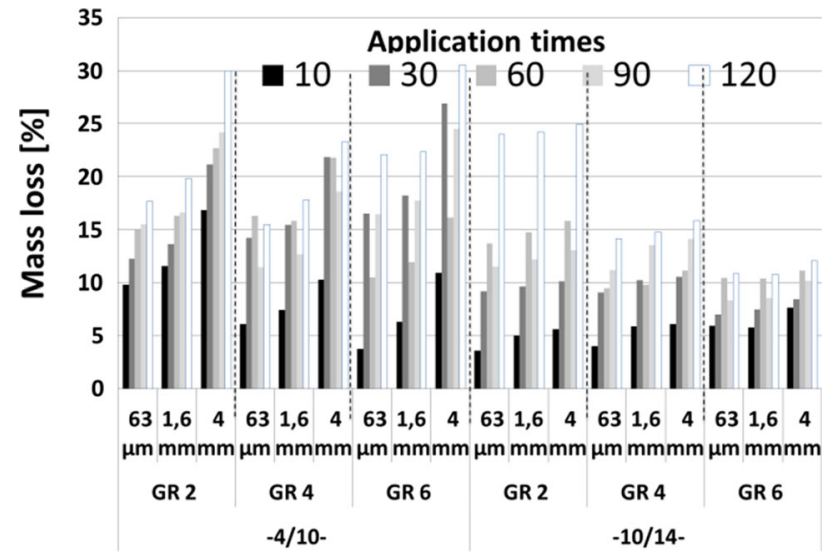

Fig. 5 Mass loss-wear test-various application times and sieve diameters

filtration generates a significant loss of material that cannot be recycled without significant processing because of the presence of residual acid. Hence, a secondary waste requiring treatment is created. Secondly, this process does not guarantee the preservation of the aggregates' quality. Indeed, the chemical reaction of hydrochloric acid with limestone aggregate is at the origin of the formation of calcium chloride and carbon dioxide.

Results in term of mass loss are of interest because they show a gap in mass loss from the $5 \mathrm{~mm}$ sieve $(4 \mathrm{~mm}$ : 26.5\%; $5 \mathrm{~mm}: 38.4 \%$ ), and stabilization with the higher sieves (6.3 mm: $38.4 \% ; 8 \mathrm{~mm}: 36.1 \%)$. It can be supposed that, up to a diameter of $5 \mathrm{~mm}$, primary aggregate are not included in the mortar. This gives an indication of the size of the post-treatment selective sieve.

\section{Hot Thermal Cycle}

\section{First Experiment: $500{ }^{\circ} \mathrm{C}$ Thermal Shock}

The heat shocks greatly weaken the mortar and they create separation between the paste and the natural aggregate.
However, natural aggregates have also been subjected to thermal shock and, so, are damaged. It is then possible to break the aggregates, manually (Fig. 8).

\section{Second Experiment: $200{ }^{\circ} \mathrm{C}+$ Ball Mill}

This first visual qualitative check shows that a large part of the removed attached mortar is now in a powder state and that gradual heating doesn't damage the primary aggregates (Fig. 8). The results of mass loss and density evolution confirm, firstly, that the mass loss criteria is insufficient to qualify the treatment efficiency. For example a mass loss of $25 \%$ (sample 2) leads to a density of $2.27 \mathrm{~g} /$ $\mathrm{cm}^{3}$ of the treated aggregate while a mass loss of $19 \%$ (sample 3) leads to a density of $2.4 \mathrm{~g} / \mathrm{cm}^{3}$ of the treated aggregate. Secondly, it is observed that a thermal treatment is beneficial to the separation of mortar and aggregate when it is added to a mechanical process. Without thermal treatment, mass loss is limited to $16 \%$ and the treated aggregate density is $2.22 \mathrm{~g} / \mathrm{cm}^{3}$. However, the applied temperature $\left(20{ }^{\circ} \mathrm{C}\right)$ is not high enough (see Fig. 8): the dilatation mechanisms and the $\mathrm{H}-\mathrm{S}-\mathrm{C}$ damage are not sufficient to ensure an efficient separation.

Third Experiment: from 105 to $600{ }^{\circ} \mathrm{C}+$ Cooling to $20^{\circ} \mathrm{C}$ + Ultrasound Post Treatment

Visual checks indicate that a temperature higher than $500{ }^{\circ} \mathrm{C}$ is required to sufficiently damage the mortar (Fig. 8). Nevertheless, ultrasound post treatment doesn't allow efficient separation of the damaged mortar from the aggregate. To compare the cooling modes' efficiency ( 0 or $20{ }^{\circ} \mathrm{C}$ ), a $2 \mathrm{D}$ image analysis is performed. The number of particles in the sample, average area and perimeters are calculated. The efficiency of a $600{ }^{\circ} \mathrm{C}$ treatment is confirmed since the area and perimeter increases come with high fragmentation: from $3075 \mathrm{~mm}^{2}$ up to $145 \mathrm{~mm}^{2}$ of area, from $239 \mathrm{~mm}$ up to $46 \mathrm{~mm}$ of perimeter and from two 


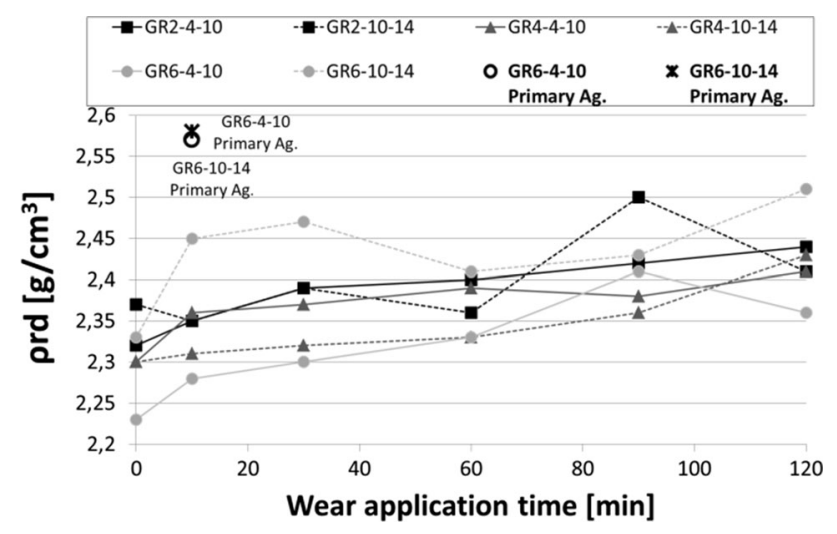

Fig. 6 Effective densities function of wear time- $1.6 \mathrm{~mm}$ sieve

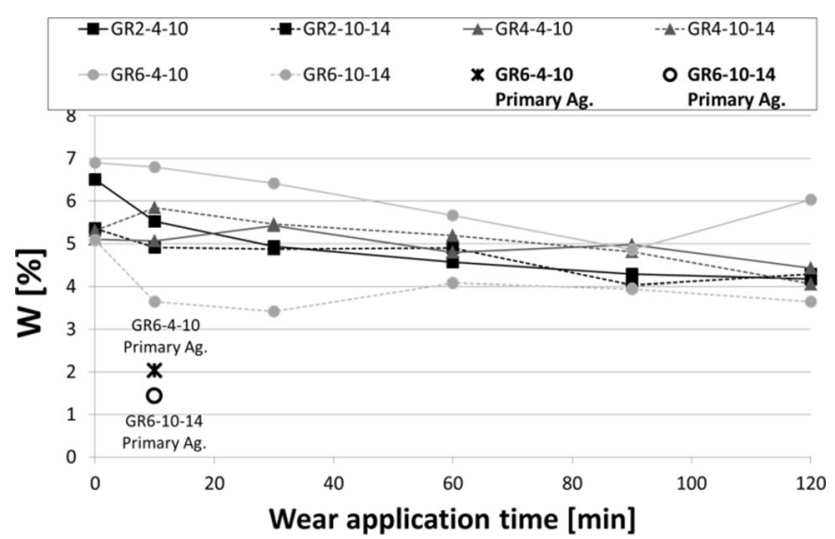

Fig. 7 Absorption coefficients function of wear time-1.6 $\mathrm{mm}$ sieve

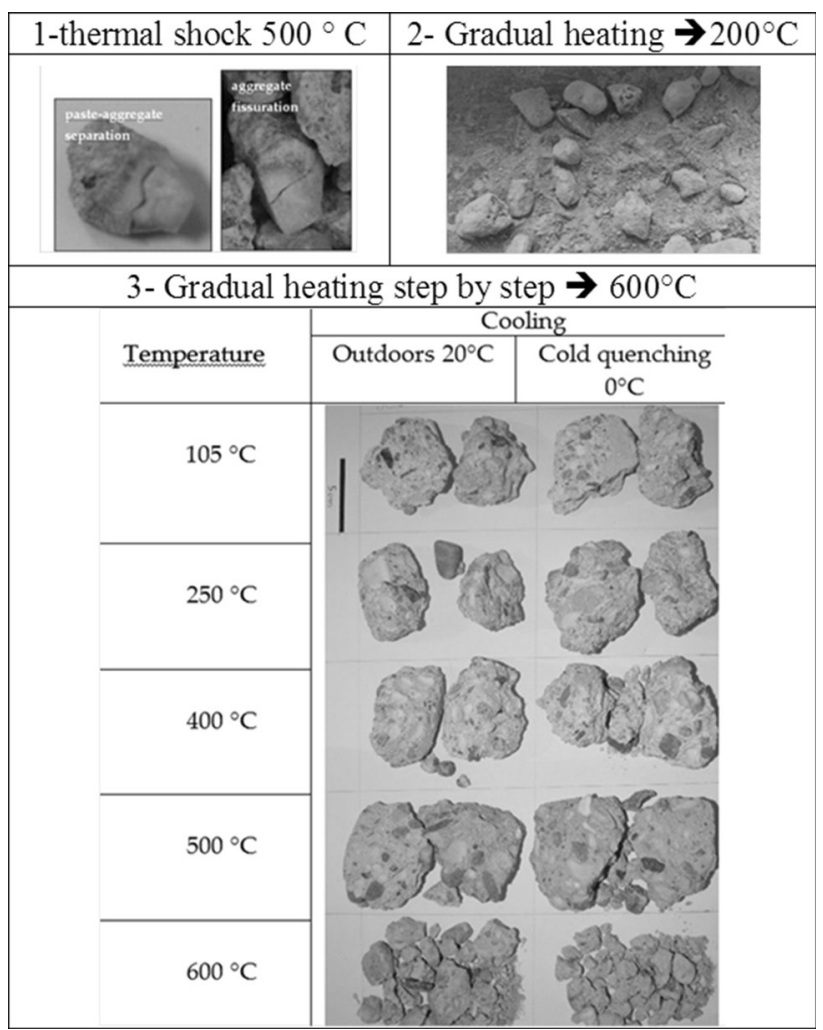

Fig. 8 Comparison of the three first hot thermal treatments

Table 7 Influence of selective sieve on evolution of density and absorption GR6-4-10 mm after mechanical treatment

\begin{tabular}{|c|c|c|c|c|c|c|c|c|c|c|c|c|c|c|c|}
\hline Application time (min) & 10 & & & 30 & & & 60 & & & 90 & & & 120 & & \\
\hline Selective sieve $(\mathrm{mm})$ & 0.063 & 1.6 & 4 & 0.063 & 1.6 & 4 & 0.063 & 1.6 & 4 & 0.063 & 1.6 & 4 & 0.063 & 1.6 & 4 \\
\hline$\rho_{\mathrm{rd}}\left(\mathrm{g} / \mathrm{cm}^{3}\right)$ & 2.25 & 2.28 & 2.35 & 2.35 & 2.30 & 2.42 & 2.36 & 2.33 & 2.34 & 2.33 & 2.41 & 2.41 & 2.31 & 2.36 & 2.40 \\
\hline $\mathrm{W}(\%)$ & 7.27 & 6.79 & 6.08 & 6.47 & 6.41 & 5.09 & 5.39 & 5.66 & 5.84 & 5.27 & 4.86 & 4.5 & 8.4 & 6.03 & 5.33 \\
\hline$\rho_{\text {rd }}$ rec. Ag. $\left(\mathrm{g} / \mathrm{cm}^{3}\right)$ & & \multicolumn{5}{|c|}{ W rec. Ag. (\%) } & \multicolumn{5}{|c|}{$\rho_{\text {rd }}$ primary Ag. $\left(\mathrm{g} / \mathrm{cm}^{3}\right)$} & \multicolumn{4}{|c|}{ W rec. Ag. (\%) } \\
\hline 2.23 & & & 6.9 & & & & \multicolumn{3}{|c|}{2.57} & & & \multicolumn{4}{|c|}{2.03} \\
\hline
\end{tabular}

$\rho_{\text {rd }}\left(\mathrm{g} / \mathrm{cm}^{3}\right)$, effective density; $\mathrm{W}(\%)$, water absorption

Table 8 Evolution of mass loss by sandblasting

\begin{tabular}{llllllll}
\hline Sample & Mass loss $(\%)$ & & & Mass loss (g) & $\begin{array}{l}\text { Sand } \\
\text { quantity }(\mathrm{g})\end{array}$ & $\begin{array}{l}\text { Sample } \\
\text { mass }(\mathrm{g})\end{array}$ \\
\hline Sandblasting time & 30 & 60 & 90 & 120 & & & \\
GR4 4/10 test 1 & 0.30 & 0.81 & 1.00 & 1.13 & 11.30 & 1381 & 1000 \\
GR4 4/10 test 2 & 0.34 & 0.80 & 1.11 & 1.29 & 25.80 & 1722 & 2000 \\
GR4 10/20 test 1 & 0.67 & 0.88 & 1.09 & 1.40 & 21.00 & 1951 & 1500 \\
GR4 10/20 test 2 & 0.39 & 0.77 & 0.83 & 1.33 & 26.70 & 1605 & 2000 \\
\hline
\end{tabular}


Table 9 Parameters and results for thermal mechanical process

\begin{tabular}{|c|c|c|c|c|c|c|c|c|c|}
\hline$\overline{\mathrm{P} 1}$ & \#Ref & $\mathrm{P} 2$ & P5 & P6 & P7 (min) & P9 & $\Delta \mathrm{m}_{\mathrm{md}}(\%)$ & $\rho\left(\mathrm{g} / \mathrm{cm}^{3}\right)$ & $\rho$ R.A. $\left(\mathrm{g} / \mathrm{cm}^{3}\right)$ \\
\hline \multicolumn{10}{|c|}{ Hot three relevant tests } \\
\hline \multirow{3}{*}{ GR4 10/20 } & 16 & No sat. & $2 \mathrm{~h}$ & Room temp. & 10 & No & 10 & 2.20 & 2.27 \\
\hline & 19.1 & No sat. & $2 \mathrm{~h}$ & Room temp. & 10 & Small & 18 & 2.29 & \\
\hline & 19.2 & No sat. & $2 \mathrm{~h}$ & Room temp. & 10 & Big & 66 & 2.37 & \\
\hline GR8 32/64 & 27.4 & Pre sat $48 \mathrm{~h}$ & $4 \mathrm{~h}$ & Ice & $5+25$ & Big + small & 58 & 2.35 & 2.14 \\
\hline \multicolumn{10}{|l|}{ Cold tests } \\
\hline \multirow[t]{9}{*}{ GR4 4/10 } & 1 & Dry & $1 \mathrm{~h} 45$ & 4 Cyc. $/ 24 \mathrm{~h} \times 4$ days & 0 & No & 1.3 & 2.27 & 2.28 \\
\hline & 2 & Dry & $1 \mathrm{~h} 45$ & 4 Cyc. $/ 24 \mathrm{~h} \times 4$ days & 2 & Mixer & 8.5 & 2.37 & \\
\hline & 3 & Dry & $1 \mathrm{~h} 45$ & 4 Cyc. $/ 24 \mathrm{~h} \times 4$ days & 10 & Abrasion & 6.9 & 2.32 & \\
\hline & 4 & Saturated & $1 \mathrm{~h} 45$ & 4 Cyc. $/ 24 \mathrm{~h} \times 4$ days & 0 & No & 3.4 & 2.34 & \\
\hline & 5 & Saturated & $1 \mathrm{~h} 45$ & 4 Cyc. $/ 24 \mathrm{~h} \times 4$ days & 2 & Mixer & 14.7 & 2.33 & \\
\hline & 6 & Saturated & $1 \mathrm{~h} 45$ & 4 Cyc. $/ 24 \mathrm{~h} \times 4$ days & 10 & Abrasion & 16.3 & 2.36 & \\
\hline & 7 & Immerged & $1 \mathrm{~h} 45$ & 4 Cyc. $/ 24 \mathrm{~h} \times 4$ days & 0 & No & 7.4 & 2.34 & \\
\hline & 8 & Immerged & $1 \mathrm{~h} 45$ & 4 Cyc. $/ 24 \mathrm{~h} \times 4$ days & 2 & Mixer & 28.5 & 2.44 & \\
\hline & 9 & Immerged & $1 \mathrm{~h} 45$ & 4 Cyc. $/ 24 \mathrm{~h} \times 4$ days & 10 & Abrasion & 34.9 & 2.44 & \\
\hline
\end{tabular}

Parameters' signification (P1-P9) are described on Figs. 3, 4

samples up to 52 samples. The results also tend to show greater efficacy using rapid cooling (89 samples, area of $137 \mathrm{~mm}^{2}$, perimeter of $40 \mathrm{~mm}$ ).

\section{Optimized Hot Thermal-Mechanical Process, First Results}

Examples of the visual checks of three relevant tests $\left(600{ }^{\circ} \mathrm{C}\right)$, and their parameters presented in Table 9, are in Fig. 9. The results of all 64 performed tests [12] are not shown here.

Test No. 16 led to a mass loss of $10 \%$. This low value is due to the presence of mortar that is detached from aggregate but is still contained in the sample (Fig. 9); As a result, the density is not increased (Table 9). For this process, the combination of a $600{ }^{\circ} \mathrm{C}$ thermal and wear mechanical treatment allows the damaging of mortar, to remove it from aggregate. However, without ball crushing, it is not sufficient to separate aggregate and mortar by sieving.

The comparison between test Nos. 19.1 and 19.2 shows the efficiency of wear post-treatment with a large ball because the density is increased, significantly. However, a mass loss of $66 \%$ induces a loss of natural primary aggregate and leads to a high quantity of secondary waste. The same results are observed for the homemade recycled 32-64 $\mathrm{mm}$ aggregate: primary aggregate density isn't recovered $\left(2.55 \mathrm{~g} / \mathrm{cm}^{3}\right)$.

\section{Cold Thermal Cycle}

First Experiment: 24 h Saturation +4 hat $-17.5^{\circ} \mathrm{C}$ Cold Cycle + Mixing

The density of the mechanically treated sample is higher $\left(2.6 \mathrm{~g} / \mathrm{cm}^{3}\right)$ than the density of the untreated sample

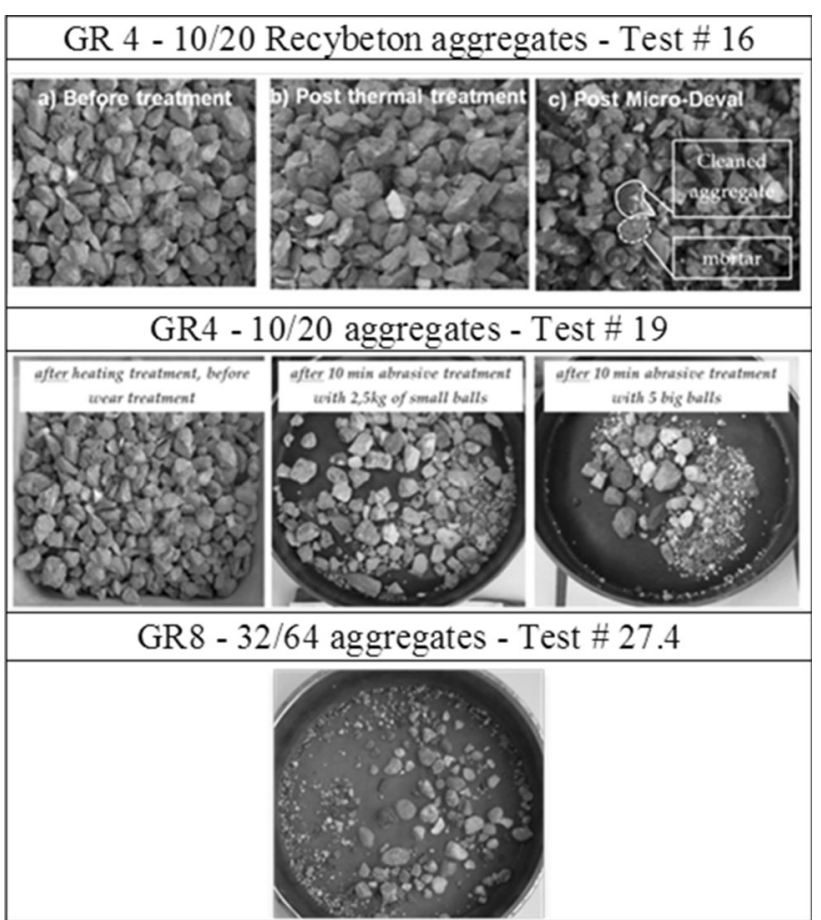

Fig. 9 Hot thermal-mechanical treatment

$\left(2.54 \mathrm{~g} / \mathrm{cm}^{3}\right)$. For this aggregate (GR4), the absolute density of primary aggregate is unknown but, usually, it is between 2.6 and $2.8 \mathrm{~g} / \mathrm{cm}^{3}$. So, a freeze/thaw cycle plus mixing allows the damaging of the attached mortar. Moreover, sieving allows the removing and separation of the said attached mortar. It appears that several aggregates are well cleaned (Fig. 10). However, the freeze $\left(-17.5^{\circ} \mathrm{C}\right)$ 


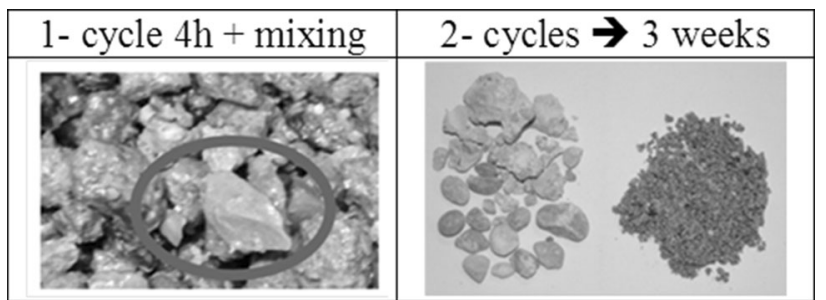

Fig. 10 Comparison of the two first cold thermal treatments

also weakens the aggregate and part of the aggregates were observed, after the mixer treatment, to have been damaged.

\section{Second Experiment: Immersion + Saturation Under Vacuum $+5{ }^{\circ} \mathrm{C} /-18{ }^{\circ} \mathrm{C}$ Freeze-Thaw Cycles + No Post- treatment}

The first heat cycle of $24 \mathrm{~h}$, without post treatment, failed to separate the aggregate cement paste. The second set of 3 -week cycles shows results of particular interest. Simple 1 and $0.16 \mathrm{~mm}$ sieving allows the separation of the aggregates and the cement paste. The majority of aggregate is cleaned (Fig. 10).

\section{Cold Thermal-Mechanical Treatment}

The most relevant results were obtained with freeze/thaw cycles " 4 cycles $/ 24 \mathrm{~h} \times 4$ days" (Table 9 ).

In the case presented, saturated and immersed aggregates present the most pertinent results with a weight loss of $34.9 \%$ and a variation in the effective density of $6.66 \%$ compared with the recycled aggregate. Results are less efficient than those obtained, previously, due to treatment duration (4 days vs 3 weeks) and applied temperature ( -10 vs $\left.-17{ }^{\circ} \mathrm{C}\right)$. The $17{ }^{\circ} \mathrm{C}$ temperature was considered as unrealizable for an industrial plant.

\section{Microwave}

An additional microwave treatment combined with a mechanical process (mixing) increases mass loss and efficiency (Fig. 11: higher absolute density). These results can be compared to those obtained with hot thermal-mechanical processes.

\section{Discussion}

\section{Efficiency Definition}

Before choosing an efficient process for the cleaning of aggregates, efficiency itself needs to be defined. Similarly, methods used for mortar content determination should define the term: mortar content.

Firstly, it's necessary to determine the sieve which is considered as selective with regards to final separation: the size considered as the maximum of one of the aggregates constituting the primary mortar. Results analysis is dependent on this choice: the higher the sieve size, the more the mass loss increases and the process could be described as very efficient. The results obtained with the mechanical process illustrate the importance of such a choice (Fig. 5). That's one of the reasons why the average mortar content of RCA, reported in the literature, present high value dispersion $[34,35]$.

Secondly, a high mass loss can be attributed to mortar damage and to the separation from primary aggregates. This can also be attributed to primary aggregate damage, as confirmed by Yoda et al. [15], in the case of mechanical process, or by Homand-Etienne and Zhao, for high temperature thermal treatment $\left(>600{ }^{\circ} \mathrm{C}\right)$ or in the case of acid treatment $[28,36]$. Thus, the technical efficiency of processes cannot be, solely, analyzed by mass loss criteria. After treatment, a check of aggregate properties is necessary. A part of the results presented here confirms that mass loss is not systematically correlated to bulk density or to $24 \mathrm{~h}$ water absorption. The same observation is reported by Akbarnezhad et al. [35], in the case of thermal treatment. Furthermore, high mass loss does not lead to clean aggregate since the density of treated aggregate is lower than that of natural aggregate (e.g. Table 8). Without knowledge
Fig. 11 Evolution of the absolute density and mass loss versus applied power (treatment MW)
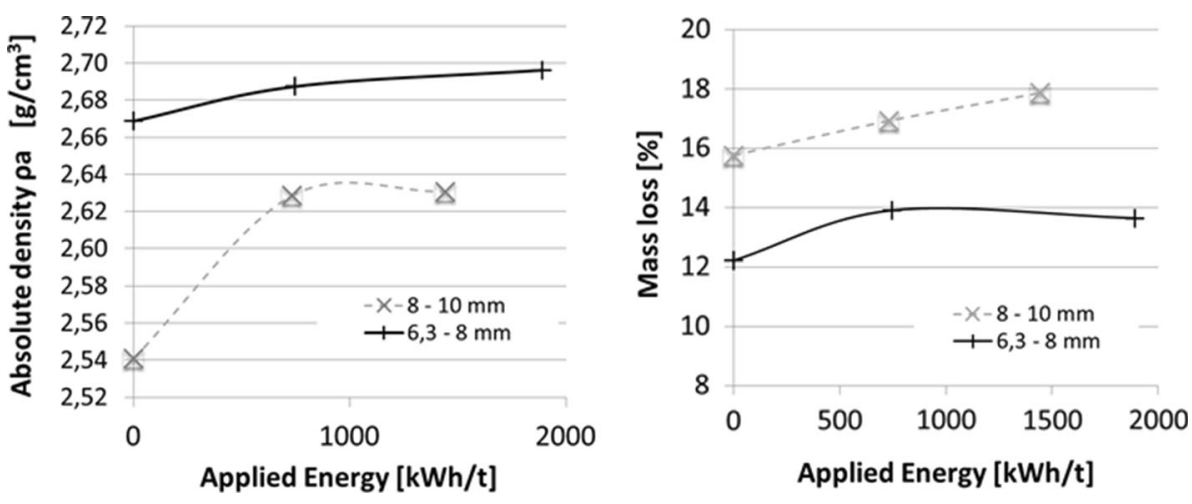
of the primary aggregates' initial properties, technical efficiency cannot be discussed, objectively. However, density values of post-treated aggregates (with a maximum of $2.44 \mathrm{~g} / \mathrm{cm}^{3}$ ), reported by Akbarnezhad et al. [35], can be compared to the usual values $\left(>2.5 \mathrm{~g} / \mathrm{cm}^{3}\right)$ and, so, are in accordance with our results.

In the same way, it's difficult to establish a comparison of our results with contents of mortar values, reported in literature. In fact, experimental procedures used to determine content, and their limits, are not always detailed [35].

When primary concrete composition is known, Dao proposes the following model to estimate mortar content [8]:

Anat $_{R C A}=\frac{\left(\rho_{R C A}-\rho_{\text {parent } C}\right)+\left(\rho_{\text {parentA }}-\rho_{R C A}\right) \times \text { Anat }_{\text {parent } C}}{\rho_{\text {parentA }}-\rho_{\text {parent } C}}$

Anat ${ }_{R A C}$ : volumetric proportion of natural aggregate in the RAC; Anat parentC $_{\text {: }}$ volumetric proportion of natural aggregate from composition of parent concrete; $\rho_{R C A}$ : RCA density; $\rho_{\text {parent } C}$ : parent concrete density; $\rho_{\text {parentA }}$ : parent aggregate density.

This simplified approach considers that the relative proportions of paste and aggregate can evolve between the primary concrete and the recycled concrete aggregate without modifying the size of the primary aggregates. That means that the employed methods do not damage the primary aggregates.

Without knowledge of primary concrete composition, an estimation of the density of the attached mortar can be done by making assumptions about its composition. However, they induce biased results. Deodonne proposes different compositions of attached mortar and measures their densities $\left(\rho_{\mathrm{d}}=1.98 \mathrm{~g} / \mathrm{cm}^{3}\right.$ for mortar, $\rho_{\mathrm{d}}=1.7 \mathrm{~g} /$ $\mathrm{cm}^{3}$ for micro-mortar and $\rho_{\mathrm{d}}=1.93 \mathrm{~g} / \mathrm{cm}^{3}$ for cement paste) [5]. Hansen [37] confirmed these values for natural aggregate and attached mortar densities $\left(\rho_{\mathrm{d}}=2.65 \mathrm{~g} / \mathrm{cm}^{3}\right.$ for natural aggregate vs $1.75 \mathrm{~g} / \mathrm{cm}^{3}$ for attached mortar).

Finally, efficiency cannot be limited to technical efficiency. Energy consumption, noise generation, health risk and the production of second generation waste have to be taken into account to distinguish efficient global processes and to compare processes. Without which, the parameters which modify the efficiency of a process cannot be analyzed. However, it is difficult to compare processes.

\section{Distinguishing Processes}

Regarding the results, it appears that individual treatment is not sufficient and that there is not any one treatment which allows the removing of all the mortar without damaging primary aggregates. Indeed, bulk density stays lower than expected for a natural aggregate while water absorption is higher. These results are in accordance with the literature: even when the most efficient treatment is applied (global efficiency), $17 \%$ of mortar is still contained in the treated aggregate [10]. According to previous discussion about efficiency definition, processes cannot be totally compared with one another or with those reported in literature.

Combining several processes can improve efficiency by combining the advantages of each one. Thus, wear by mechanical processes (MDE wear) is efficient for an application time of at least $30 \mathrm{~min}$. These results are in accordance with those mentioned by Yoda [15]. The processing duration and, also, high energy consumption is necessary to achieve a minimal efficiency of abrasion treatment by shocks ( $20 \mathrm{~min}$ for Los Angeles test). Thermal processes allow the damaging of mortar by hot thermal stresses and by mineral phase destruction but, as shown in Fig. 8, a temperature higher than $500{ }^{\circ} \mathrm{C}$ (up to $600{ }^{\circ} \mathrm{C}$ ) is required to damage enough mortar, specially portlandite, according to Fig. 12 [38]. Homand-Etienne and Houper, confirm that a temperature of $600{ }^{\circ} \mathrm{C}$ is needed [36].

To conclude, concerning the efficiency of pre-saturation or rapid cooling in ice after heating, as presented by Bazant and Kaplan [21] and confirmed by De Juan and Gutierrez [39], the whole experiment design of the hot thermalmechanical process proposed needs to be performed and analyzed with the aim of identifying the relevant parameters. Similarly, the application of damage by freeze-thaw cycles on primary mortar, mainly by thermal stresses and the expansion of ice (Table 8) and with a high saturation state, improves efficiency as confirmed by the results of Yang et al. [22]. Low energy micro wave application or sandblasting, used alone, are inefficient. However, they could be combined for a first post treatment. Chemical attack by acid is efficient regarding technical objectives but cannot be applied to an industrial plant because of the health and environmental impact. The use of this process must be limited to check the quantity of mortar content in the laboratory if primary aggregates do not react to acid, as studied by Zhao [28].

Combining the advantages of each process, described above, leads to the thermal-mechanical treatments proposed here, or, by Shima et al. [19] or Nogushi [31]. They appear to be the most promising processes on condition that the method is sequenced step by step as proposed in this study, and can be described as the follow: hot or cold heat treatment to damage mortar//wear by mechanical treatment to unstick mortar and to crush it to reduce size aggregates//micro wave application with low energy, ultrasound or sandblasting applied simultaneously or, before sieving, in order to separate constituents provided that the selected sieve is defined//a quality check by measuring the properties of cleaned aggregates (densities, absorption, mechanical strengths). At this time, visual 
Fig. 12 Thermal differential analysis of concrete [38]

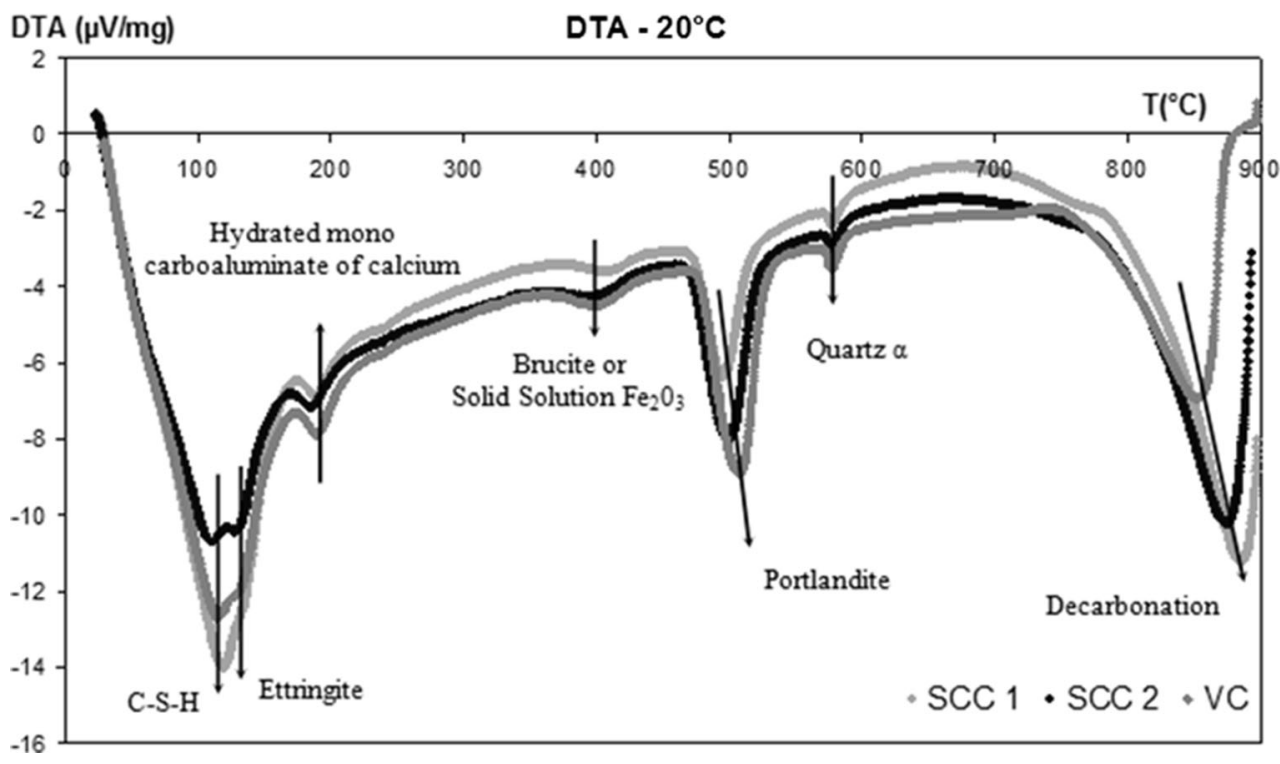

checks are still the most appropriate method for analyzing the cleanness of aggregate although observation can be subjective. In this sense, more recent studies performed since this study suggest adding a sequenced step of visual sorting to select cleaned aggregates. The mass percentage of cleaned aggregates that can be reused compared to treated recycled aggregate is low (19\%). However, the aggregates obtained are of appropriate quality. Moreover, $24 \%$ of treated aggregates are cleaned but broken, $18 \%$ of treated aggregates are composed of mortar and $27 \%$ of treated aggregates are partially cleaned. The rest is composed of fine elements. Eerland and Florea propose also a combination of processes (pressure plus abrasion), leading to easily recyclable aggregates although no control on the properties of the treated aggregates were performed $[16,17]$. Such a global process including the optimization of the initial crushing is interesting on condition that properties and qualities of the treated aggregates are controlled.

\section{Conclusions and Further Study}

Thanks to a short preliminary process review, this study allows the identifying of relevant treatments depending on the most appropriate separation of mortar and/or of the most appropriate quantification of the attached mortar of RCA. These selected methods, or combinations of them, are then tested in the laboratory in order to determine their efficiency. Their efficiency is analyzed using mass loss, density variation measurements and visual comparison.

First, it appears that, in order to distinguish an efficient process for aggregate treatment, efficiency itself needs to be defined (mass loss or density measurement vs cleaned aggregates ratio). In the same way, the constitution of primary mortar should be defined (the maximum aggregate size of which it is constituted). Furthermore, the process efficiency is difficult to determine because of the lack of knowledge of primary aggregate properties. As a major objective of this study is to develop methods in the laboratory which are transferable on a wider scale, global efficiency needs to take into account not only the technical criteria of cleanness but also the environmental and industrial criteria.

Experimental results indicate that aggregates are never completely cleaned and/or can be damaged by the applied treatments. Thus, no method is $100 \%$ satisfactory. However, combined processes, such as the thermal-mechanical treatment proposed here, appear to be the most promising processes on condition that the method is sequenced step by step.

The next steps of this study will consist in performing the two complete experimental designs of thermal mechanical experiments (hot and cold) and the multi-criteria analysis in order to determine, step by step, the relevant value of parameters. In order to improve the definition of the efficiency and the cleanness of the aggregates, many checks will be performed, such as density and absorption measurements, visual checks, mechanical strength, grading curves, etc. Thus, their non-damaging properties or the evolution of their properties will be verified. Then, the environmental impact, especially energy consumption of the optimized processes, will be determined to ensure appropriate industrial application.

Acknowledgements The authors would like to thank the members of the French national recybeton project for providing the RCA samples. The authors also wish to acknowledge Mr. Danko Mandić for his 
contribution to the realization of the tests and COLAS (laboratory of Heillecourt, France) who allowed us to perform the sandblasting tests.

\section{References}

1. Vandecasteele, C., Heynen, J., Goumans, H.: Materials recycling in construction: a review of the last two decades illustrated by the Wascon conferences. Waste Biomass Valoriz. 4, 695-701 (2013)

2. Coronado, M., Dosal, E., Coz, A., Viguri, J.R., Andrés, A.: Estimation of construction and demolition waste (C\&DW) generation and multicriteria analysis of C\&DW management alternatives: a case study in Spain. Waste Biomass Valoriz. 2, 209-225 (2011)

3. Serres, N., Braymand, S., Feugeas, F.: Environmental evaluation of concrete made from recycled concrete aggregate implementing life cycle assessment. J. Build. Eng. 5, 24-33 (2016)

4. Braymand, S., Roux, S., Kunwufine, D., Mihalcea, C., Feugeas, F., Fond, C.: Recycled aggregates concrete: a high development potential material in concrete. In: Matériaux 2014 p. 10 , Montpellier (2014)

5. Deodonne, K: Studies of the physicochemical characteristics of recycled aggregate concrete and their environmental impact. $\mathrm{PhD}$ Thesis, Strasbourg University (2015)

6. Tsoumani, A.A., Barkoula, N.-M., Matikas, T.E.: Recycled aggregate as structural material. Waste Biomass Valoriz. 6, 883-890 (2015)

7. Braymand, S., François, P., Feugeas, F., Fond, C.: Rheological properties of recycled aggregate concrete using superplasticizers. J. Civ. Eng. Archit. 9, 591-597 (2015)

8. Dao, D.-T.: (Multi-) recycling of hydraulic concrete. PhD Thesis, Central School of Nantes, p. 309. IFFSTAR (2012)

9. Sri Ravindrarajah, R., Tam, C.T.: Recycling concrete as fine aggregate in concrete. Int. J. Cem. Compos. Lightweight Concr. 9, 235-241 (1987)

10. Torgal, F.P., et al. (eds.): Handbook of Recycled Concrete and Demolition Waste. Woodhead Pub, Cambridge (2013)

11. Thomas, J.J., Jennings, H.: Materials of cement science primer TEA-21 year 5 final report

12. French National Project Recybeton. http://www.pnrecybeton.fr/

13. Afnor, Norme NF EN 1097-2: Tests for mechanical and physical properties of aggregates: methods for the determination of resistance to fragmentation, p. 34 (2010)

14. Afnor, Norme NF EN 1097-1: Tests for mechanical and physical properties of aggregates: methods for the determination of the resistance to wear (micro-deval), p. 14 (2011)

15. Yoda, K., Harada, M., Sakuramoto, F.: Field Application and Advantage of Concrete Recycled In Situ Recycling Systems, pp. 437-446. Thomas Telford Serv. Ltd, London (2003)

16. Eerland, D.: Recycling of concrete 2.0. In: 9th International Conference on the Environmental and Technical Implication of Construction with Alternative Materials, Wascon. Santander, Spain (2015)

17. Florea M.V.A., Ninig Z., Brouwers H.J.H.: Smart crushing of concrete and activation of liberated concrete fines. TU/e. Final report (2014)

18. Linß, E., Mueller, A.: High-performance sonic impulses-an alternative method for processing of concrete. Int. J. Miner. Process. 74, S199-S208 (2004)

19. Shima, H., Tateyashiki, H., Matsuhashi, R., Yoshida, Y.: An advanced concrete recycling technology and its applicability assessment through input-output analysis. J. Adv. Concr. Technol. 3, 53-67 (2005)

20. Akbarnezhad, A., Ong, K.C.G., Tam, C.T., Zhang, M.H.: Effects of the parent concrete properties and crushing procedure on the properties of coarse recycled concrete aggregates. J. Mater. Civ. Eng. 25, 1795-1802 (2013)

21. Bazant, Z.P., Kaplan, M.F.: Concrete at high temperatures: material properties and mathematical models. Longman, Burnt Mill, England (1996)

22. Yang, Z., Brown, H., Cheney, A.: Influence of moisture conditions on freeze and thaw durability of Portland cement pervious concrete. In: Concrete Technology Forum: Focus on Pervious Concret, pp. 24-25. Citeseer (2006)

23. Rønning, T.F.: Freeze-thaw resistance of concrete: effect of curing conditions, moisture exchange and materials, doctoral thesis, Norvegian University of Science and Technologies (2001)

24. Menard, Y., Bru, K., Touze, S., Lemoign, A., Poirier, J.E., Ruffie, G., Bonnaudin, F., Von Der Weid, F.: Innovative process routes for a high-quality concrete recycling. Waste Manag. 33, 1561-1565 (2013)

25. Tasong, W.A., Lynsdale, C.J., Cripps, J.C.: Aggregate-cement paste interface. Cem. Concr. Res. 29, 1019-1025 (1999)

26. Akbarnezhad, A., Ong, K.C.G., Zhang, M.H., Tam, C.T., Foo, T.W.J.: Microwave-assisted beneficiation of recycled concrete aggregates. Constr. Build. Mater. 25, 3469-3479 (2011)

27. Tam, V.W.Y., Tam, C.M., Le, K.N.: Removal of cement mortar remains from recycled aggregate using pre-soaking approaches. Resour. Conserv. Recycl. 50, 82-101 (2007)

28. Zhao, Z., Wang, S., Lu, L., Gong, C.: Evaluation of pre-coated recycled aggregate for concrete and mortar. Constr. Build. Mater. 43, 191-196 (2013)

29. Akbarnezhad, A., Ong, K.C.G., Zhang, M.H., Tam, C.T.: Acid treatment technique for determining the mortar content of recycled concrete aggregates. J. Test. Eval. 41, 20120026 (2013)

30. Momber, A.W.: Aggregate liberation from concrete by flow cavitation. Int. J. Miner. Process. 74, 177-187 (2004)

31. Nogushi: Proceedings of Session in Honor of Dr. Enrico Borgarello, Professor Theodore W. Bremner, Professor David W. Fowler, Professor Konstantin Kovler, Professor Koji Sakai. Second International Conference on SCMT, Ancona (2010)

32. Dean, S.W., Abbas, A., Fathifazl, G., Burkan Isgor, O., Razaqpur, A.G., Fournier, B., Foo, S.: Proposed method for determining the residual mortar content of recycled concrete aggregates. J. ASTM Int. 5, 101087 (2008)

33. Afnor, N.: NF EN 197-1 Composition, specifications and conformity criteria for common cements, p. 36 (2012)

34. Li, X.: Recycling and reuse of waste concrete in China: part I. material behaviour of recycled aggregate concrete. Resour. Conserv. Recycl. 53, 36-44 (2008)

35. Akbarnezhad, A., Ong, K.C.G.: Separation processes to improve the quality of Recycled Concrete Aggregates (RCA). In: Pacheco-Torgal, F., Tam, V., Labrincha, J., Ding, Y., de Brito, J (eds.) Handbook of Recycled Concrete and Demolition Waste, pp. 246-269. Elsevier, Amsterdam, The Netherlands (2013)

36. Homand-Etienne, F., Houpert, R.: Thermally induced microcracking in granites: characterization and analysis. Int. J. Rock Mech. Min. Sci. Geomech. Abstr. 26, 125-134 (1989)

37. Hansen, T.C.: Recycled aggregates and recycled aggregate concrete second state-of-the-art report developments 1945-1985. Mater. Struct. 19, 201-246 (1986)

38. Fares, H., Remond, S., Noumowe, A., Cousture, A.: High temperature behaviour of self-consolidating concrete: microstructure and physicochemical properties. Cem. Concr. Res. 40, 488-496 (2010)

39. De Juan, M.S., Gutiérrez, P.A.: Study on the influence of attached mortar content on the properties of recycled concrete aggregate. Constr. Build. Mater. 23, 872-877 (2009) 